\title{
Entamoeba gingivalis (Gros, 1849) and Trichomonas tenax (Muller, 1773) oral infections in patients from Baixada Fluminense, province of Rio de Janeiro, Brazil
}

\author{
Claudia Maria Blanco Moreira Norberg ${ }^{1}$, Paulo César Ribeiro ${ }^{1}$, Nathália Satyro-Carvalho², \\ Fabiano Guerra Sanches ${ }^{3}$, Raimundo Wilson de Carvalho ${ }^{1,4}$, Antonio Neres Norberg ${ }^{5}$ \\ ${ }^{1}$ Biological and Health Sciences School, Iguaçu University, UNIG, Nova Iguaçu, Rio de Janeiro State, Brazil \\ ${ }^{2}$ Grande Rio University, UNIGRANRIO, Rio de Janeiro, Rio de Janeiro State, Brazil \\ ${ }^{3}$ Brazilian Army Health School, Rio de Janeiro, Rio de Janeiro State, Brazil \\ ${ }^{4}$ Department of Biological Science, Sérgio Arouca National Public Health School, FIOCRUZ, Rio de Janeiro, Rio de Janeiro State, Brazil \\ ${ }^{5}$ UNIABEU University Center, Belford Roxo, Rio de Janeiro State, Brazil
}

\author{
Email address: \\ norberg@uol.com.br (C. M. B. M. Norberg), ribeiroribeirop@uol.com.br (P. C. Ribeiro), \\ nathy_carvalho@hotmail.com (N. Satyro-Carvalho),fab.gs@bol.com.br (F. G. Sanches), \\ raimundo.carvalho@pesquisador.cnpq.br (R. W. Carvalho), norberg@uol.com.br (A. N. Norberg)
}

\section{To cite this article:}

Claudia Maria Blanco Moreira Norberg, Paulo César Ribeiro, Nathália Satyro-Carvalho, Fabiano Guerra Sanches, Raimundo Wilson de Carvalho, Antonio Neres Norberg. Entamoeba Gingivalis (Gros, 1849) and Trichomonas Tenax (Muller, 1773) Oral Infections in Patients from Baixada Fluminense, Province of Rio de Janeiro, Brazil. Science Journal of Public Health. Vol. 2, No. 4, 2014 , pp. $288-292$. doi: $10.11648 /$ j.sjph.20140204.17

\begin{abstract}
This paper describes the patterns of Entamoeba gingivalis and Trichomonas tenax oral infection within the Baixada Fluminense, neighborship of Rio de Janeiro city, province of Rio de Janeiro, Brazil, assessed by the number of persons parasitized with or without periodontites, emphasizing the variables: gender, age, $\mathrm{pH}$ of the saliva, smoking habit and the total number of teeth in the mouth. The Baixada Fluminense is composed by 13 municipalities in the Rio de Janeiro metropolitan region and is characterized by economic, social and educational substandards as well as inadequate sewerage, a result of the abandonment of regional public policy. Amoeba infection was common to all individuals, decreasing with age $\left(r^{2}=0.92, p<0.05\right)$ in healthy individuals but increasing with age in people with periodontal disease $\left(r^{2}=0.97, p<0.05\right)$. Additionally, there was co-infection by amoeba and flagellate protozoa in 51 individuals, and monoparasitism only by amoeba in the remaining 49 patients, 27 in the control group (without periodontitis) and 22 in the case group (with periodontitis). The prevalence of flagellate infection was $51.0 \%$ (51 out of the 100 individuals in both groups), unassociated with either group $(\chi 2=0.2, p>0.05)$ or among genders $(\chi 2=1.2, p>0.05)$. The flagellate infection decreased with age in the control group and increased with age in those who were ill. Periodontitis is an important variable to consider in amoeba and flagellate infections as the risk factor increased $13 \mathrm{x}$ in older patients, in spite of the non-significant statistical result ( $\mathrm{p}>0.05)$. Both infections emerged at neutral $\mathrm{pH}(5.5-7.0)$. While the healthy group cases of infection reached the prevalence peak at $\mathrm{pH}$ 6.5 , the case group did so at 6.0 , a insignificant difference. Considering only the T. tenax infection, the dental records of the control group registered low absence of teeth, a striking difference from group members with periodontal disease, each of which missed teeth ranging between one and all. Furthermore, E. gingivalis and T. tenax infections increased when there is tooth absence $($ E. gingivalis $\mathrm{rs}=0.97$; T. tenax $\mathrm{rs}=0.99, \mathrm{p}<0.05)$, indicating a positive correlation between tooth loss and both infections. Out of the 100 examined patients, eighteen (18\%) were active smokers and, among them, eight (44\%) were $T$. tenax positive. Although this represents only $8 \%$ of the total sample, all of the smokers belonged to the periodontal disease group.
\end{abstract}

Keywords: Entamoeba gingivalis, Trichomonas tenax, Periodontitis, Baixada Fluminense, Brazil 


\section{Introduction}

The oral cavity of humans hosts an important flora microcosm of bacteria, fungi, virus and protozoa. The protozoa, Trichomonas tenax and Entamoeba gingivalis, usually proliferates on the surface of teeth and gums associated with gingival pockets near the base of the teeth and in the tonsils. The flagellate, T. tenax, is considered nonpathogenic and is common in $10 \%$ of the population, mainly related to poor mouth hygiene. In the same way, the amoeba is associated with periodontal disease and is abundant in cases of gum and tonsil diseases, but there is no evidence indicating their involvement in the etiology of these conditions. Therefore, these parasites are linked to various pathological conditions in the tonsils, lungs, neck and pre-existing oral diseases, such as periodontitis, favored by the use of prostheses and orthodontic appliances [1-6].

The absence of cystic forms requires that the main form of transmission be through direct personal contact, the amoeba usually by kissing, droplet spray or shared eating utensils. Up to $95 \%$ of the population with poor oral hygiene may be infected with Entamoeba gingivalis [7]. However, indirect contamination may occur through sharing food, cups, cutlery and other fomites [8,9]. Many years have passed since the first descriptions of these protozoa, and various aspects of the morphology, biology, diagnosis and pathogenesis remain poorly understood. So, considering the lack of information on epidemiological factors of these protozoosis, we decided to investigate the patterns of these parasitic infections correlating with the common characteristics of the public health in the Baixada Fluminense region, considering the patients of the Iguaçu University Dental Policlinic.

\section{Materials and Methods}

The prevalence of E. gingivalis and T. tenax in oral infections in individuals under treatment in the Clinical Dentistry of the University Iguaçu (UNIG) was studied through clinical examination of the oral cavity and parasitological exams of the fluid obtained from the oral cavity. From 365 patients under treatment in the clinic in 2011 , one hundred (27.4\%, 51 men and 49 women) were separated into two groups, 50 in each group comprised of both male and female, the first considered the control group (I) with healthy gingiva and the other (II) with periodontal disease.

All patients were requested to rinse the mouth with $5.0 \mathrm{~mL}$ of sterile saline solution for approximately one minute and, soon afterwards, spit this fluid into sterile vials duly dated and identified. The salivary $\mathrm{pH}$ was measured in these vials with a universal indicator paper strip Merck ${ }^{\circledR}$. At the laboratory, the material was centrifuged (500rpm) for five minutes and the supernatant discharged. A drop of sediment from each tube was prepared on slides and analyzed with optical microscopy $(400 x)$; the interval between saliva collection and microscopic examination not exceeding two hours, as recommended by Corrêa et al. [10]. Positive slides were considered those which displayed the trophozoites of protozoa regarding their specific characters.

The data were analyzed by the BioStat 5.0 computer program with the chi-square test to infer differences in the infection between group I (without periodontites), II (with periodontites) and gender. The goodness-of-fit linear regression $\left(\mathrm{r}^{2}\right)$ between the number of cases of protozoa infection and age group was adopted to determine the increase or decrease of the prevalence according to age, the spearman correlation (rs) to determine increase or decrease of the protozoa infections in relation to saliva $\mathrm{pH}$ and finally, the Fischer test to evaluate the relation of infection to tabagism. The statistical significance was set at $\mathrm{p}<0.05[11]$.

Ethical considerations: All experiments on humans were conducted in accordance with the Declaration of Helsinki as well as the opinion of the ethics committee of Iguaçu University. So, all participants were informed about the adopted procedures and were required to sign appropriate consent forms.

\section{Result}

Table 1. Trichomonas tenax Müller, 1773 oral infection stratified by sex and individuals with and without periodontal disease. Clinical dentristry of the Iguaçu University, Baixada Fluminense, province of Rio de Janeiro, Brazil.

\begin{tabular}{|c|c|c|c|c|c|}
\hline \multirow{3}{*}{$\begin{array}{c}\text { Gender / Prevalence } \\
\text { in groups }\end{array}$} & \multicolumn{5}{|c|}{ Group I (control group) } \\
\hline & \multirow{2}{*}{$\begin{array}{c}\text { Total of the sample } \\
\text { No. }\end{array}$} & \multicolumn{2}{|c|}{ Positive } & \multicolumn{2}{|c|}{ Negative } \\
\hline & & No. & $\%$ & No. & $\%$ \\
\hline Men & 28 & 12 & 42.8 & 16 & 57.2 \\
\hline Women & 22 & 11 & 50.0 & 11 & 50.0 \\
\hline $\begin{array}{l}\text { Total and prevalence } \\
\text { in Groups I }\end{array}$ & 50 & 23 & 46.0 & 27 & 54.0 \\
\hline \multicolumn{6}{|c|}{ Group II (case group) } \\
\hline Men & 13 & 9 & 69.2 & 4 & 30.8 \\
\hline Women & 37 & 19 & 51.3 & 18 & 48.7 \\
\hline $\begin{array}{l}\text { Total and prevalence } \\
\text { in Group II }\end{array}$ & 50 & 28 & 56.0 & 22 & 44.0 \\
\hline Overall prevalence & 100 & 51 & 51.0 & 49 & 49.0 \\
\hline
\end{tabular}

All the one hundred participants in this research were infected by the E. gingivalis amoeba, of which fifty one individuals presented co-infection by both the amoeba and $T$. tenax flagellate protozoa, the remaining 49 patients infected only by the amoeba alone, 27 in the control and 22 in the case group. The amoeba infection decreased with age $\left(\mathrm{r}^{2}=0.92, \mathrm{p}<0.05\right)$ in patients with healthy gums whereas increased with age in those with periodontal disease $\left(\mathrm{r}^{2}=0.97\right.$, $\mathrm{p}<0.05$ ) (Fig.1). The prevalence of flagellate infection was $51.0 \%$ (51 out of the 100 individuals of both groups), unassociated with either group $(\chi 2=0.2, \mathrm{p}>0.05)$ or among genders $(\chi 2=1.2, \quad \mathrm{p}>0.05)$. The flagellate infection 
decreased with age in the control group and increased with age in group II (Table 1) (Fig. 2). Therefore, periodontal disease is an important variable to consider in both amoeba and flagellate infections. Both infections arose predominantly at neutral $\mathrm{pH}$ ranging from 5.5 to 7.0. While the healthy group infection cases reached the peak of prevalence at $\mathrm{pH}$ 6.5, group II was registered at 6.0 indicating a negligible difference (Fig.3).

The dental records of the healthy group members (control group) described low absence of teeth ranging from zero to seven, establishing a striking difference from those with periodontal disease (group II) with absence of various teeth ranging from one to all. The flagellate infection was common in both groups, prevalence of $46.0 \%$ and $56.0 \%$ in groups I and II, respectively. There was no association regarding the prevalence of the T. tenax infection compared with gender considering the number of teeth $\left(\chi^{2}=1.0\right.$, $\mathrm{p}>0.05$ ). Similarly, there was not an association with the flagellate infection and the absence of teeth ( $\mathrm{p}$-Valor $=0.44$, $\alpha>0.05$ ) (Table 2). Moreover, E. gingivalis and T. tenax infections increased with tooth absence (E. gingivalis $\mathrm{rs}=$ $0.97 ;$ T. tenax $\mathrm{rs}=0.99, \mathrm{p}<0.05)$. About the 100 examined patients, eighteen $(18 \%)$ were active smokers, of which eight (44\%) were infected by $T$. tenax, all belonging to the periodontal disease group.
Table 2. Trichomonas tenax Müller, 1773 oral infection stratified according to the number of teeth. Clinical dentistry of Iguaçu University, Baixada Fluminense, province of Rio de Janeiro, Brazil.

\begin{tabular}{|c|c|c|c|}
\hline \multirow{3}{*}{$\begin{array}{l}\text { No. of teeth } \\
\text { (unit) }\end{array}$} & \multicolumn{3}{|c|}{ Group I (control group) } \\
\hline & \multirow{2}{*}{$\begin{array}{l}\text { Absoluty and } \\
\text { relative } \\
\text { frequency of } \\
\text { individuals }\end{array}$} & \multicolumn{2}{|c|}{ Trichomonas tenax } \\
\hline & & Positive (\%) & Negative $(\%)$ \\
\hline $1-8$ & - & - & - \\
\hline $9-16$ & - & - & - \\
\hline $17-24$ & - & - & - \\
\hline $25-32$ & 50 & $23(46.0)$ & $27(54.0)$ \\
\hline \multirow[t]{2}{*}{ Total (\%) } & $50(100)$ & $23(46.0)$ & $27(54.0)$ \\
\hline & \multicolumn{3}{|c|}{ Group II (case group) } \\
\hline $1-8$ & 2 & $1(50.0)$ & $1(50.0)$ \\
\hline $9-16$ & 5 & $4(80.0)$ & $1(20.0)$ \\
\hline $17-24$ & 18 & $9(50.0)$ & $9(50.0)$ \\
\hline $25-32$ & 25 & $14(56.0)$ & $11(44.0)$ \\
\hline \multirow{2}{*}{ Total (\%) } & $50(100)$ & $28(56.0)$ & $22(44.0)$ \\
\hline & $100(100)$ & $51(51.0)$ & $49(49.0)$ \\
\hline
\end{tabular}

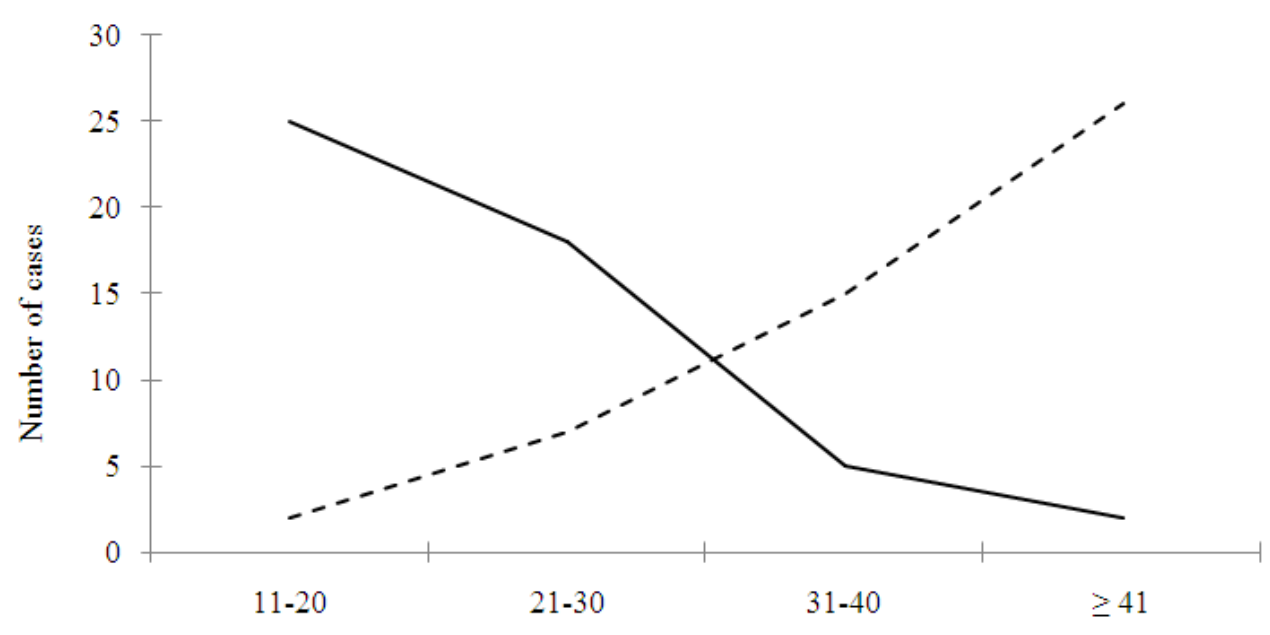

Age group

- Group I(control group), $\mathrm{r}^{2}=0.92, \mathrm{p}<0.05$

Fig. 1. Goodness-of-fit linear regression between the number of cases of Entamoeba gingivalis (Gros, 1849) infection and age group. Clinical dentristry of the Iguaçu University, Baixada Fluminense, province of Rio de Janeiro, Brazil. 


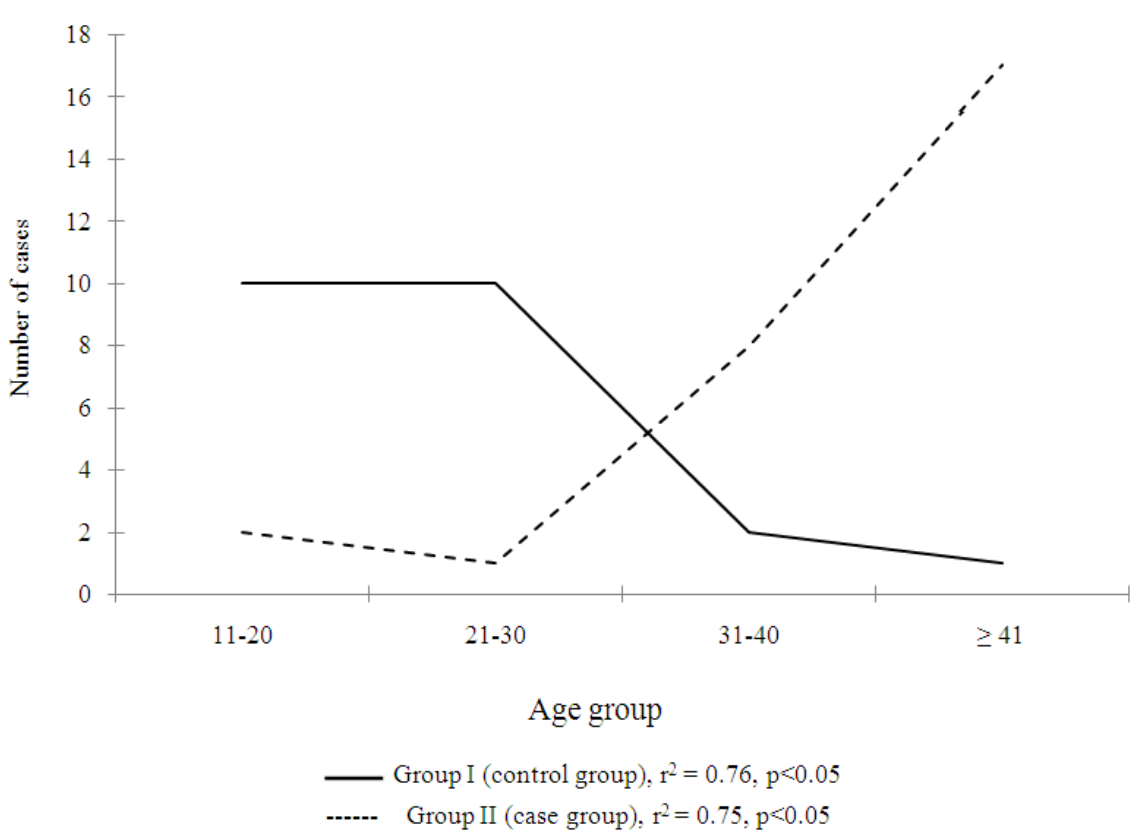

Fig. 2. Goodness-of-fit linear regression between the number of cases of Trichomonas tenax Müller, 1773 infection and age group. Clinical dentistry of the Iguaçu University, Baixada Fluminense, province of Rio de Janeiro, Brazil.

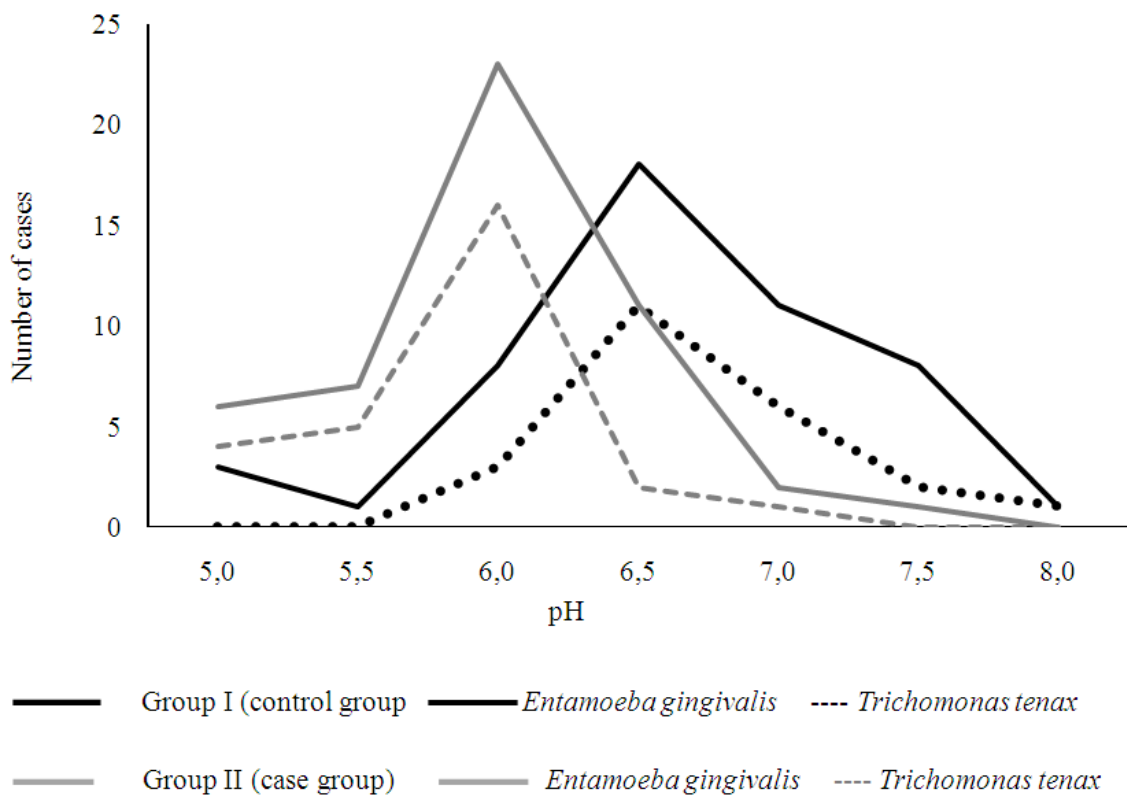

Fig. 3. The Entamoeba gingivalis (Gros, 1849) and Thichomonas tenax Müller, 1773 infections stratified according to the pH of the saliva. Clinical dentistry of Iguaçu University, Baixada Fluminense, province of Rio de Janeiro, Brazil.

\section{Discussion and Conclusions}

The Baixada Fluminense is composed of 13 municipalities in the Rio de Janeiro metropolitan region and is economically considered an important industrial area [12]. This region has suffered severe socio-economic changes in the last decades. Nowadays, the region is characterized by economic, social and underdevelopment, low quality of life of the inhabitants and by inadequate sewerage, as results of ineffective public policies [13, 14]. Considering this scenario, the authors recomends the necessity for a public policy for oral heath in this region, although it was not the principal aim of this manuscript.

The overall prevalence of periodontal disease was $79.2 \%$ ( 289 with periodontitis) in 365 patients being treated at the beginning of this survey and was considered as high as that reported by Coutinho and Tostes-Amaral [15] in a study in the metropolitan region of Rio de Janeiro City as well as by Chambrone et al. [16] which published an entire review of epidemiological surveys on periodontal diseases in Brazil, reporting that $86.7 \%$ individuals examined had evidence of marginal gingivitis or periodontal damage. In this paper the prevalence of amoeba (100\%) and flagellate (51\%) indicates that periodontal disease is an important variable to consider 
in flagellate and amoeba infection (Table 1).

The examined group is composed by randomly chosen patients treated at the Clinical dentistry of Iguaçu University. All individuals examined hosted E. gingivalis and $51(51.0 \%)$ hosted T. tenax, $23(46.0 \%)$ in the healthy and $28(56.0 \%)$ in the afflicted group. So, it was clear that the two parasites must be responsible for the periodontitis, as detected in other countries in Africa and Asia [17]. Moreover, both infections are highly associated with age [18] (Fig. 1 and 2). The Entamoeba gingivalis and Trichomonas tenax oral protozoa are not found in infants and children. However, in post puberty, the infection rate seems to be ever increasing, associated with oral cavity evolution favoring inflammation, particularly, in diseased gums, tooth tartar, carious teeth and in patients with high teeth loss (Table 1 and 2). The highest incidence has been recorded in adults with periodontitis and/or atrophy of the periodontium, and somewhat lower in adults with gingivitis, especially those patients with poor dental hygiene $[19,20]$.

The salivary $\mathrm{pH}$ ranged from 5.0 to 8.0 ; the highest prevalence of infection by the two protozoa was between 6.0 and 6.5. Considering the two studied groups, the incidence of infection gradually decreased as the oral $\mathrm{pH}$ became more alkaline as observed by Albuquerque-Júnior et al. (2011) [3] (Fig.3).

\section{Acknowledgements}

To the participants of this research, patients of the Clinical Dentistry of the University Iguaçu (UNIG) and thanks to Mitchell Raymond Lishon, native of Chicago, Illinois, U.S.A.-U.C.L.A. 1969, by the english review and revision.

\section{References}

[1] L. Chiche, S. Donati, G. Corno, S. Benoit, I. Granier, M. Chouraki, "Trichomonas tenax in pulmonary and pleural diseases,” Press. Me. Vol.34, p.1371, 2005.

[2] H. Okada, T. Matsumato, K. Miyuki, T. Nakahira, M. Omura, H. Yamamoto, "Clinico pathological and cytolological study of Entamoeba gingivalis," J. Japan. Soc. Clin. Cytol. Vol. 41, pp. 321-326, 2002.

[3] R.L.C. Albuquerque-Júnior, C.M. Melo, W.A. Santana, J.L. Ribeiro, F.A. Silva, "Incidence of Entamoeba gingivalis and Trichomonas tenax in samples of dental biofilm and saliva from patients with periodontal disease," Rev. Gaúcha Odontol. Vol. 59, pp. 35-40, 2011.

[4] J. Bo, S.A. Kolansky, W.B. Zubair, K.G. Prabodh, "Entamoeba gingivalis pulmonary abscess - Diagnosed by fine needle aspiration,” Cyto. Jour. Vol. 5, pp. 89-91, 2008.

[5] J. Ghabanchi, M. Zibaei, M.D. Afkar, A.H. Sarbazie, "Prevalence of oral Entamoeba with periodontal disease and healthy population in Shiraz, southern Iran," Indian J. Dental Research. Vol. 21, pp. 89-91, 2010.
[6] O. Hiroyuki, M. Takasha, M. Miyuki, N. Takayuki, O. Mitsuhiro, Y. Hirotsugu, "Clinicopathological and cytological study of Entamoeba gingivalis", J. Jap. Soc. Clin. Pathol. Vol. 41: pp. 321-326, 2002.

[7] L.S. Roberts, J.R.J Janovy, D. Gerald, L. Schmidth. S. Roberts, "Foundations of Parasitology, $6^{\text {th }}$ ed., Mcgraw Hills: Companies, 2000, pp. 670.

[8] M. Cambon "Etude de la fréquence des protozoaries de des levures de la cavité bucalle chez l'homme," Actual Odontostomatol. Vol.130, pp. 279-286, 1980.

[9] L. Cechova, I. Leifertova, M. Lisa "The incidence of Entamoeba gingivalis in the oral cavity," Acta Univ. Carol. Vol. 33, pp. 549-559, 1987.

[10] D.P. Corrêa, J.F. Giazzi, I. Martinez "Proposta de uma nova técnica de detecção de Entamoeba gingivalis e Trichomonas tenax," Rev. Ciênc. Farm. Vol. 19, pp. 245-249, 1998.

[11] M. Ayres, M. Jr. Ayres, D.L. Ayres, A.S. Santos, BioEstat 5.0. Aplicação Estatística nas Áreas das Ciências Biológica e Médica, Sociedade Civil Mamirauá, Brasília, 2005, 272 pp.

[12] M.R. Simões, A Cidade Estilhaçada: Reestruturação Econômica e Emancipações Municipais na Baixada Fluminense. Programa de Pós-Graduação em Geografia, Universidade Federal Fluminense, Rio de Janeiro, Brasil, 2006, 286pp.

[13] Unesco. Human development reports. Hdr.nb undp.org-en-reports-global-hdr2011-download-pt

[14] F.A.O. Cruz "Educational performance and family income: Comparative study in Baixada Fluminense," Vivências, Vol. 8, pp. 92-99, 2012.

[15] T.C.L. Coutinho, M.A. Tostes-Amaral. "Prevalência de gengivite em crianças,” Rev.Gaúcha de Odontologia, Vol.45, pp. 170-174, 1997.

[16] L. Chambrone, A.P.A. Lima, L.A.Chambrone "Prevalence of periodontal disease in Brazil. II. 1993-2003" Rev. Odonto, Vol. 31, pp. 69-76, 2008.

[17] J. Ghabanchi, M. Zibaei, M.D. Afkar, A.H. Sarbazie. "Prevalence of oral Entamoeba gingivalis and Trichomonas tenax in patients with periodontal disease and healthy population in Shiraz, Southern Iran," Indian J. Dent. Res. Vol. 21, pp. 89-91, 2010.

[18] J. Sarowaska, D. Wojnicz, H. Kaczkowski, S. Jankowski "The occurrence of Entamoeba gingivalis and Trichomonas tenax in patients with periodontal disease, Immunosupression and genetic diseases," Adv. Clin. Exp. Med. Vol. 13, pp. 291-297, 2004.

[19] A.E. Onyido, E.S. Amadi, I. Olofin, A.A. Onwumma, I.C. Okoh, C.I. Chikwendu "Prevalence of Entamoeba gingivalis and Trichomonas tenax among dental patients attending Federal School of Dental Technology and Therapy clinic, Enugu, Nigeria," Nature \& Science. Vol. 9, pp. 59-62.

[20] J. Vráblic, S. Tomová, G. Catár “ Occurrence of the protozoa, Entamoeba gingivalis and Trichomonas tenax in the mouths of children and adolescents with hyperplastic gingivitis caused by phenytoin," Bratisl. Lek. Listy. Vol. 93, pp. 136-140, 1992. 